teing flat for adherence to rocks is closed in so as to hold a small mass of air. Suspended by the buoy so formed, they float at the surface mouth downwards. The one of which a figure is now on the screen Minyas carulea, is remarable as being one of the small band of Pelagic animals which is coloured deep blue. There are also Pelagic insects of the genus Halobates of the Bug family, and closely allied to the common water bugs which skip on the surfaces of our ponds. Halobates is found clinging to the surface of the waves at all distances from land in the open oceans, and outrides the heaviest storms.

There are many Pelagic fishes; I have already shown you the dolphin (Coryphæna). Here is a figure of one of the Ribbon Fishes, the scarce Regalecus. This fish has usually been supposed to be a pelagic fish, but Dr. Gunther is persuaded that it is a true deep-sea fish, though it has not yet been caught in any deep-sea net, only picked up dead cn the surface. There are many similar fishes about which some difference of opinion as yet exists as to their habits. The young of the Ribbon Fishes are found alive at the sea surface, and the group may therefore perhaps yield another instance of the connection of Pelagic with deep-sea forms. The Pelagic snakes are interesting as, to some extent, modern representatives of the Eocene sea serpents (Titanophis), for though they come on shore to produce their young, their existence is mostly spent at the sea surface often far from land, and they are specially modified both in the structure of their lungs, and the ribbonlike flattening of their tails for pelagic existence.

There is one lizard, the well known Amblyrhynchus of the Galapagos Islands, described by Mr. Darwin in his Journal, which though it cannol in any way be termed pelagic swims out to sea, and as the only recent one which does so is worth mention as a sort of representative of the gigantic pelagic lizards of Mesozoic periods such as Mososaurus.

With so many groups of the animal kingdom contributing to the Pelagic fauna, it is remarkable that some large groups should be entirely unrepresented within it. There are no adult Pelagic sponges, no Alcyonarians, no Sipunculids, no Brachiopods, no Lamellibranchs, and lastly no Echinoderms. Considering the curious adaptations to Pelagic life which have been undergone by such forms as sea anemonies, nemertines, compound as cidians and gasteropods, it is most easy to conceive how Lamellibranchs for example taking after the habit of flying as it were butterfly fashion thrc ugh the water like Lima hyans, might have become Pelagic, and how Echini taking after Minyas, or Comatulæ swimming with their arms or Holothurians in various ways might have assumed a Pelagic dress, but no Lamellibranch, and no Echinoderm seems ever in the long record of the past to have been Pelagic since the time of their earliest Pelagic ancestors, unless possibly Saccoma of the lithographic state was Pelagic.

With regard to the history of the Pelagic fauna in the past. There can te no doubt, as Prof. Weissmann so well puts it, that "the birth place of all animal and plant life lay in the sea." It is probable that a considerable part of earliest life which existed must have been Pelagic, and that the ancient Pelagic fauna was to a large extent the parent of all other life. The developmental history of all marine animals points clearly in this direction, closely similar transparent Pelagic larval forms being common to groups of widely different adult littoral forms. The resemblance between the larvæ of these adult forms can hardly be conceived to have been arrived at by natural selection after the adult forms had already diverged from one another. It is only to be explained on the hypothesis of an original Pelagic ancestral condition. One of tire Monera, Protomyxa aurantiaca, is even now a Pelagic form, having been found by Prof. Haeckel adhering to a floating spirula shell.

From the recent interesting researches of Dr. Nathorst, ${ }^{x}$ we know that Scyphomedusæ clcsely like those now swimming in Southampton Water, were already amongst the Pelagic fauna of the Cambrian Sea, whilst the mud at the same time swarmed with annelids very similar to those now existing. At the same remote epoch Brachiopods, Corals, Echinoderms, Crustacea, and other forms were already present on the coasts.

The Precambrian Pelagic fauna must therefore probably have contained sexually mature representatives of the Planula, the Bilateral Echinoderm larva, the Ephyra (which survives as such to the present day), the 'irochosphere and the Nauplius. During the Cambrian feriod or earlier, was added the Cypris ancestor of Cirripeds, and the vertel rate ancestor, and the Trilobite Eglina with gigantic eyes found its place in the dim light somewhere, ${ }^{I}$ Svenska Vetensk. Akad. Hand., No. 7, Bd. xviii. possibly amongst the Pelagic fauna. In Silurian times Pteropods were added to the Pelagic throng, some gigantic forms of which nearly a foot in length are now extinct, whilst one genus then present still flourishes in modern seas, the Heteropods also appeared (Bellerophon) and Cirriped larvæ, and the Graptoliths, possibly Pelagic, appeared and became extinct. In the Devonian period certain sharks and rays and ganoid fishes probably took to Pelagic life. Pelagic representatives of the sharks and rays still flourish, but the ganoids have retreated to the fresh waters. In the early Secondary period Globigerina appeared and a few Radiolarians, and the dibranchiate cephalopods came into being and soon the sea swarmed with the Pelagic Belemnites. The air-breathing reptiles whose ancestors had quitted sea life and gone on shore came back to Pelagic life and the Ichthyosaurus with enormous eyes chased the Pelagic prey in the depths, or hunted at night. Somewhat later the ancestors of the Mososaurids took to the sea ; and their progeny became entirely Pelagic and as huge as whales.

In early tertiary times, or shortly before that, various mammalia took to the sea, and amongst them the whales became entirely pelagic and relinquished the shore aliogether. Some animals have apparently taken to oceanic life, in very recent times indeed. Ianthina is an instance in point, it has not as yet been discovered in the fossil condition at all, nor any close allies of it.

Somewhat thus has the Pelagic fauna grown up, having been partly composed of animals : the ancestry of which has probably led a Pelagic life from the earliest times, and partly added to, at all ages by inhabitants of the coast, and the dry land which have as it were from time to time run away to sea.

In conclusion, I can only say that it has given me the greatest pleasure to address a lecture to you on the present subject in a city, the population of which is itself so largely Pelagic. It is to a considerable extent through the careful collecting of the Captains of merchant vessels interested in zoology on the high seas, who have gathered sfecimens for the Museums of their home ports, that many of the facts I have laid before you tonight have teen brought to light, and all praise is due to them for the fact.

\section{UNDERGROUND TEMPERATURE}

THE Underground Temperature Committee of the British Association have presented a summary (drawn up by Prof. Everett) of the results contained in all their reports (fifteen in number) up to the present date, of which the following is an abridgment :-

The results are classified under the heads: A. Instruments. B. Methods of observation. C. Questions affecting correctness of observations. D. Questions affecting deductions from observations. E. Comparison of results. F. Mean rate of increase of temperature with deptb, and mean upward flow of heat.

A. Instruments.-Under this head we have: I. Instruments for observing temperature. 2. Subsidiary apparatus.

I. The thermometers which the Committee have employed have been of two kinds-slow-action thermometers and maximum thermometers. The present pattern of slow-action thermometer consists of a thermometer having its bulb surrounded by stearine or tallow, the whole instrument being hermetically sealed within a glass jacket, and had its origin in a conference between the secretary and Dr. Stapff in the St. Gothard Tunnel.

Cur present patterns of maximum thermometer are two-the Phillips, and the Inverted Negretti-both being hermetically sealed in strong glass jackets to prevent the bulbs from receiving pressure when lowered to a great depth in water.

Both instruments are used in a vertical position, and they register truly in spite of jolts in hauling up.

References to Becquerel's thermo-electric method of observing underground temperature were made in three of the reports, and some laboratory experiments were subsequently carried out by the secretary, which led to the conclusion that the method could not be relied on to yield sufficiently accurate results. It may be mentioned that Becquerel's observations are only carried to the depth of roo feet, whereas we require observations at the depth of 1000 or 2000 feet.

2. Under the head of subsidiary (that is non-thermometric) 
apparatus, plugs for preventing convection-current in a bore or well are referred to. Prof. Lebour's umbrella-like plug, in its final form, appears to be very convenient, as it requires only one wire. It remains collapsed so long as the wire is taut, but opens out and plugs the hole when it becomes slack.

B. Methods of ObServation. - These have chiefly been of two kinds: I. Observations in holes bored to the depth of a few feet in newly-opened rock, either in the workings of a mine or a tunnel, or in a shaft during the sinking. The rock should not have been exposed for more than a week when the hole is bored, and a day may be allowed to elapse for the heat generated by boring to escape before the thermometer is inserted. Very complete plugging is necessary to exclude the influence of the external air. It is desirable to use about two feet of plugging, of which the outer part should be made air-tight with plastic clay or greased rag. After the lapse of a few days, the thermometer is to be drawn out by means of a string attached to the handle of its copper case, and the reading taken. The slowaction thermometer above described is employed for this purpose, and there is time to read it with sufficient deliberation before any appreciable change occur; in its indication. It is recommended that the thermometer be then reinserted and plugged as before, and a second reading taken after the lapse of a week. The majority of our successful observations have been made by this method.

2. Observations in deep bores of small diameter. The first report contained a successful application of this method to a bore about 350 feet deep, near Glasgow, which gave very regular results in a series of observations at every sixtieth foot of depth; but in the majority of instances in which it has since been applied, there have been marked irregularities, due apparently to the influx of water from springs at particular points. One of the most valuable of our results was obtained by the application of the method to a bore 863 feet deep, executed at the bottom of a coal mine 1066 feet deep, giving a total depth of 1929 feet. The bore in this case was dry at the time of its execution, though full of water at the time of the observation. It was in South Hetton Colliery, Durham. The instrument generally employed in the observations of this class was a maximum thermometer of either the Phillips or the Inverted Negretti construction.

The larger the diameter of the bore, the more uncertain does this mode of observation become. The South Hetton bore had a diameter of $2 \frac{1}{2}$ inches. The Kentish Town well, rooo feet deep, in which Mr. Symons' observations were made, had a diameter of 8 inches, and the well 660 metres deep at La Chapelle, in the north of Paris, had a diameter of $4 \frac{1}{6}$ feet (V., VI., VII.). The temperatures in this last were proved to be largely affected by convection, the water at the top being too warm, and that at the bottom not warm enough. The observations of Herr Dunker, in the bore at Sperenberg, near Berlin, with a depth of $339^{\circ}$ feet and a diameter of 12 inches, proved a similar disturbance, amounting at the top and bottom, to several degrees. As regards the bottom, the proof consisted in showing that when a thermometer at the bottom was protected by a tight plug from the influence of the water above, its indications were higher by $3^{\circ} \mathrm{R} .\left(=6_{4}^{\circ} \mathrm{E}\right.$.) than when this precaution was not employed.

C. Questions AfFecting THE Correctness of THE OBSERVATIONS MADE might theoretically include questions as to the correct working of the instruments employed, and as to the personal reliability of observers; but the latter topic has not come into discussion, and the former has not arisen since our present patterns of instrument came into use. The questions for discussion are thus jconfined to those which relate to possible differences between the temperature "of the point at which the thermometer was placed and the normal temperature at the same depth in its vicinity.

r. The heat generated by the action of the boring tool will vitiate the observation if sufficient time is not allowed for its escape.

A very full discussion of this subject in connection with the great artesian well at $\mathrm{La}$ Chapelle will be found in reports V., VI., and VII., clearly establishing the fact that the temperature at the bottom both on the third and the sixth day after the cessation of boring operations, was $7 \frac{1}{4}^{\circ} \mathrm{F}$. higher than after the lapse of four months, though the water had been left to itself during this interval. Further evidence showing that the temperature in the lower part of a bore full of water may thus be raised several degrees, is furnished by the Sub-Wealden bore.

2. The generation of heat by local chemical action is well known to be a powerful disturbing cause when pyrites is present. The observers in the mines of Schemnitz say, "Pyrites and also decaying timber were avoided, as being known to generate heat." The observations in the coal mines of Anzin show a temperature of $70_{4}^{30} \mathrm{~F}$. in shaft IV. (a very dry one) at the depth of $21^{\circ} 2$ metres, or less than 70 feet. This must be about $15^{\circ} \mathrm{F}$. above the normal temperature. In shaft II. the observer mentions that there was, at a de th of $90 \mathrm{~m}$, a seam of coal in which heat was generated by oxidation.

At Talargoch lead mine, in Flintshre, the discrepancies between the temperatures at the six observing stations are suggestive of local chemical action.

3. Convection of heat has proved a very troublesome disturbing cause.

As to convection of heat by air in a shaft or well not filled with water, evidence will be found in the second report, both in the case of Mr. Hunter's observations in the shafts of two salt mines at Carrickfergus, having the depths of 570 and 770 feet respectively, and in the case of $\mathrm{Mr}$. Symons' observations at Kentish Town, where the first 2 ro feet of the well are occupied with air. At the depth of 150 feet the temperature was $52^{\circ} I$ in January, and 54.7 in July.

Convection of heat by water in old shafts which have been allowed to become flooded, is very manifest in some of the observations communicated by Mr. Burns in the second and fourth reports. In Allendale shaft (Northumberland), 300 feet deep, with about 1 go feet of water, the temperature was practically the same at all depths in the water, and this was also the case in Breckon Hill Shaft, where the observations extended from the depth of 42 feet to that of 350 feet. A similar staie of things was found in a shaft at Ashburton (Devon) by Mr. Amery, who observed at every fiftieth foot of depth down to 350 feet.

Convection by water in the great well at La Chapelle, $660 \mathrm{~m}$. ( 2165 feet) deep, and $\mathrm{I} \cdot 35 \mathrm{~m}$. ( 4 feet 5 inches) in diameter at the bottom, appears probable from the following comparisons :-

Very concordant observations (communicated by M. Walferdin to Comptes rendus for 1838 ) at three different wells in the Paris basin of the respective depths of $263 \mathrm{~m}$., $400 \mathrm{~m}$., and $600 \mathrm{~m}$., show by comparison with one another and with the constant temperature in the artificial caves under the Paris Observatory a rate of increase of $1^{\circ} \mathrm{F}$. in 56 or 57 feet. These data would give, at the depth of $100 \mathrm{~m}$., or 328 feet, a temperature of $57^{\circ}$, and at the depth of $660 \mathrm{~m}$., or 2165 feet, a temperature of $90^{\circ}$; whereas the temperatures actually observed at those depths in the well at La Chapelle in October, 1873 , when the water had been undisturbed for a year and four months, were $59^{\circ} \cdot 5$ and $76^{\circ}$. It thus appears probable that the upper part of the well is warmed, and the lower part cooled, by convection. Further light may be expected to be thrown on this point when the well reaches the springs, and the water spouts above the surface, as it does at the Puits de Grenelle. A letter received by the secretary in July, 1882, states that engineering difficulties have prevented any deepening of the well since the above observations, but that arrangements for this purpose have now been made.

More certain and precise information as to the effect of convection in deep bores is furnished by the experiments of Herr Dunker at Sperenberg. The principal bore at Sperenberg has a depth of 4052 Rhenish, or 4172 English feet, and is entirely in rock salt, with the exception of the first 283 feet. Observations were first taken (with a maximum thermometer on the overflow principle) at numerous depths, from roo feet to the bottom, and showed a fairly regular increase of temperature downwards. The temperature at 700 feet was $16^{\circ} \circ 8 \mathrm{R}$., and at $339^{\circ}$ feet $34^{\circ} \cdot \mathrm{I} \mathrm{R}$. Plugs were then contrived which could be fixed tight in the bore at any depth with the thermometer between them, or could be fixed above the thermometer for observing at the bottom. Convectior was thus prevented, and a difference of one or two degrees Réaumur was found in the temperature; at most of the depths; at 700 feet the temperature was now $17^{\circ} .06 \mathrm{R}$., and at 3390 feet $36^{\circ} \cdot 15$. We have thus direct evidence that convection had made the temperature at 3390 feet $2^{\circ} \cdot 05$ R., or $4^{\circ} \cdot 6 \mathrm{~F}$. too low ; and this, as Herr Dunker remarks, is an under-estimate of the error, inasmuch as convection had been exerting its equalising action for a long time, and its effect could not be completely destroyed in the comparatively short time that the plugs were in position. Again, as regards the effect of convection on the upper part of the bore, the temperature $\mathrm{II}^{\circ} \circ \mathrm{O} \mathrm{R}$ was observed at the depth of 100 feet in the principal bore when no plugs wexe employed, while a second bore only roo feet deep in its imme- 
diate vicinity showed a temperature $9^{\circ} \circ \mathrm{R}$, at the bottom. This is direct evidence that the water near the top of the great bore had been warmed $2^{\circ} \mathrm{R}$., or $4^{\circ}{ }^{\circ} \mathrm{F}$. by convection.

Suggestions for observations in filled-up bores will be found in the elcventh report, but they have not yet taken a practical shape.

D. Questions affecting Deductions from ObservaTIONS. - I. In many instances the observations of temperature have been confined to considerable depths, and in order to deduce the mean rate of increase from the surface downwards it has been necessary to assume the mean temperature of the surface. To do this correctly is all the more difficult, because there seems to be a sensible difference between the mean temperature of the surface and that of the air a few feet above it.

In the third report some information on this point is given, based on observations of thermometer 32 inches deep at some of the stations of the Scottish Meteorological Society, and of thermometers 3 (French) feet deep at Greenwich and at Edinburgh. These observations point to an excess of surface-tem. perature above air-temperature, ranging from half a degree to nearly two degrees, and having an average value of about one degree.

Dr. Schwartz, Professor of Physics in the Imperial School of Mines at Schemnitz, in sending his observations made in the mines at that place, remarks on this point :-

"Observations in various localities show that in sandy soils the excess in question amounts, on the average, to about half a degree Centigrade. In this locality the surface is a compact rock, which is highly heated by the sun in summer, and is protected from radiation by a covering of snow in winter; and the conformation of the hills in the neighbourhood is such as to give protection against the prevailing winds. Hence the excess is probably greater here than in most places, and may fairly be assumed to be double the above average."

Some excellent observations of underground temperature at small depths were made at the Botanic Gardens, Regent's Park, London, for the six years $1871-76$, along with observations of air-temperature, and have been reduced by Mr. Symons. They are at depths of $3,6,12,24$, and 48 inches beneath a surface of grass, and their joint mean derived from readings at 9 a.m. and 9 p.m. for the six years is $49^{\circ} 9$, the mean for the 48 .inch thermometer being $50^{\circ} 05$. The mean air-temperature derived in the same way from the readings of the dry-bulb thermometer is $49^{\circ} 6$. Hence it appears that the excess of soil above air is in this case about $0^{\circ} 4$.

Quetelet's observations for three years at Brussels (p. 48 of his "Mémoire") make the earth, at depths less than $I_{2}^{\frac{1}{2}}$ foot, colder than the air, and at greater depths warmer than the air.

Caldecott's observations for three years at Trevandrum, in India, make the ground at the depth of 3 feet warmer than the air by $5^{\circ} .7 \mathrm{~F}$.

Dr. Stapff, in his elaborate publications on the temperature of the St. Gothard Tunnel, arrives at the conclusion that the mean temperature of the soil on the surface of the mountain above the tunnel is some derrees higher than that of the air, the excess increasing with the height of the surface and ranging from $2^{\circ}$ or $3^{\circ} \mathrm{C}$. near the ends of the tunnel, to $5^{\circ}$ or $6^{\circ}$ in the neighbour hood of the central ridge.

2. Connected with this is the question-Whether the mean annual temperature of the soil increase; downwards from the surface itself, or whether, as is sometimes asserted, the increase only begins where annual range ceases to be sensible-say at a depth of 50 or 60 feet.

The general answer is obvious from the nature of conduction. Starting with the fact that temperature increases downwards at depths where the annual range is insensible, it follows that heat is travelling upwards, because heat will always pass from a hotter to a colder stratum. This heat must make its way to the surface and escape there. But it could not make its way to the surface unless the mean temperature diminished in approaching the surface; for if two snperposed layers had the same mean temperature, just as much heat would pass from the upper to the lower as from the lower to the upper, and there would not be that excess of upward flow which is necessary to carry off the perennial supply from below.

This reasoning is rigorously true if the conductivity at a given depth be independent of the temperature, and be the same all the year round. By "conductivity" we are to understand the "flux of heat" divided by the "temperature-gradient"; where by the "flux of heat" is meant the quantity of heat which flows in one second across unit-area at the depth considered, and by the "temperature-gradient" is meant the difference of tempera. ture per foot of descent at the depth and time considered.

Convection of heat by the percolation of water is here to be regarded as included in conduction. If the conductivity as thus defined were the same all the year round, the increase of mean temperature per foot of depth would be independent of the amnual range, and would be the same as if this range did not exist.

As a matter of fact, out of six stations at which first-class underground thermometers have been observed, five show an increase downwards, and one a decrease. The following are the results obtained for the depths of 3,12 , and 24 French feet :-

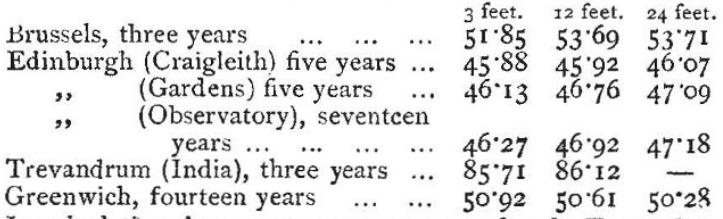

In calculating the mean temperature at 12 feet for Trevandrum, we have assumed the temperature of May, which is wanting, to be the same as that of April.

Omitting Trevandrum, aud taking the mean values at 3 and 24 French feet, we find an increase of 656 of a degree in 21 French feet, which is at the rate of $I^{\circ}$ for 32 French, or about 34 English fee:.

3. Another question which it has sometimes been necessary to discuss is the inflaence which the form of the surface exerts on the rate of increase of temperature with depth.

The surface itself is not in general isothermal, but its temperature is least where its elevation is greatest; the rate of decrease upwards or increase downward; being generally estimated at $I^{\circ}$ $\mathrm{F}$. for 300 feet. This is only about one-fifth of the average rate of increase downwards in the substance of the earth itself beneath a level surface. If the two rates were the same, the isotherms in the interior of a mountain would be horizontal, and the form of the surface would have no influence on the rate of increase of temperature with depth. The two extreme assumptions that the surface is an isotherm, and that the isotherms are horizontal, lie on opposite sides of the truth. The isotherms, where they meet the sides of the mountain, slope in the same direction as the sides of the mountain, but to a less degree. Probably the tangents of the two slopes are generally about as 3 to 4 .

Further, if we draw a vertical line cutting two isotherms, the lower one must have less slope than the upper, because the elevations and depressions are smoothed off as the depth increases.

The practical inference is that the distance between the isotherms (in other words, the number of feet for $\mathrm{I}^{\circ}$ of increase), is greatest under mountain crests and ridges, and is least under bowl-shaped or trough-shaped hollows.

The observations in the Mont Cenis tunnel, and the much more complete observations made by Dr. Stapff in the St. Gothard tunnel, fully bear out these predictions from theory. The discussion of the former occurs in the fourth report, p. I5.

As regards the St. Gothard tunnel, Dr. Stapff reports :"The mean rate of increase downwards in the whole length of the tunnel is 02068 of a degree Centigrade per metre of depth, measured from the surface directly over. This is $\mathbf{I}^{\circ}$ F. for 88 feet. Where the surface is a steep ridge the increase is less rapid than this average ; where the surface is a valley or plain the increase is more rapid."

4. The question whether the rate of increase downwards is upon the whole the same at all depths, was raised by Prof. Mohr $\mathrm{i}$, his comments upon the Sperenberg observations, and is discussed, so far as these observations bear upon it, in the $9^{\text {th }}$ and IIth reports.

Against the Sperenberg observations, which upon the whole show a retardation of the rate of increase as we go deeper, may now be set the Dukinfield observations begun by Sir William Fairbairn, and continued by Mr. Garside. Taking Mr. Garside's observations, and assuming a surface-temperature of $49^{\circ}$ the increase in the first $1987 \frac{1}{2}$ feet is at the rate of $1^{\circ}$ in 79.5 feet ; in the next 420 feet it is at the rate of $1^{\circ}$ in 70 feet, and in the last $283 \frac{1}{2}$ feet it is at the rate of $1^{\circ}$ in $51 \frac{1}{2}$ feet.

From a theoretical point of view, in places where there is no local generation of heat by chemical action, the case stands thus :-

The flow of heat upwards must be the same at all depths, and this flow is equal to the rate of increase downwards, multiplied 
by the conductivity, using the word "conductivity" (as above explained) in such a sense as to include convection. The rate of increase downwards must, therefore, be the same at all depths at which this corductivity is the same.

This reasoning applies to superposed strata at the same place, and assumes them to be sufficiently regular in their arrangerent to ensure that the flow of heat shall be in parallel lines, not in converging or diverging lines.

5. If we have reason to believe that the flow of heat upwards is nearly the same at all places, then the abo:e reasoning can also be applied approximately to the comparison of one place with another-that is to say, the rates of increase downwards, in two masses of rock at two different places, must be approximately in the inverse ratio of their conductivities. In the cooling of a heated sphere of heterogeneous composition, the rates of flow would at first be very unequal through different parts of the surface, being most rapid through those portions of the substance which conducted best; but these portions would thus be more rapidly drained of their heat than the other portions, and thus their rates of flow. would fall off more rapidly than the rates of flow in the other portions. If the only differences in the material were differences of conductivity, we might on this account expect the outflow to be after a long time nearly the same at all parts of the surface. But when we come to consider differences of "thermal capacity per unit volume," it is clear that with equal values of "diffusivity," that is of " conductivity divided by thermal capacity of unit volume" in two places, say in two adjacent sectors of the globe, there would be the same distribution of temperatures in both, but not the same flow of heat, this latter being greatest in the sector in which the capacity and conductivity were greatest.

Where we find, as in Mr. Deacon's observations at Bootle, near Liverpool, and to a less marked degree in the observation of Sir William Fairbairn and Mr. Garside, near Manchester, an exceptionally slow rate of increase, without exceptionally good conductivity, it is open to us to fall back on the explanation of exceptionally small thermal capacity per unit volume in the underlying region of the earth, perhaps at depths of from a few miles to a-few hundred miles.

6. A question which was brought into consideration by Prof. Hull, in connection with the great difference between the rate of increase at Dukinfield and that at Rosebridge, is the effect of the dip of the strata npon the vertical conduction of heat. Laminated rocks conduct heat much better along the planes of lamination than at right angles to them. If $k_{1}$ denote the conductivity along, and $k_{2}$ the conductivity normal to the planes of lamination, and if these planes are inclined at an angle $\theta$ to the horizon, the number of feet per degree of increase downwards correrponding to a given rate of outflow through the surface, will be the same as if the flow were vertical with a vertical conductivity :-

$$
k_{1} \sin ^{2} \theta+k_{2} \cos ^{2} \theta \text {. }
$$

Prof. Herschel finds about $I^{\cdot} 3$ as the ratio of the two principal conductivities in Loch Rannoch flagstone, and 1.875 as the ratio in Festiniog slate.

The dip of the strata at Dukinfield is stated by Mr. Garside to be $15^{\circ}$, and we have $\sin ^{2} 15^{\circ}=\circ{ }^{\circ} 07, \cos ^{2} 15^{\circ}={ }^{\circ} 93$.

If we assume $k_{1}=\mathrm{I} \cdot 3 k_{2}$, as in the case of flagstone, we find for the effective vertical conductivity $k_{2}\left({ }^{\circ} \mathrm{O} 9+{ }^{\circ} 93\right)=\mathrm{I} \cdot \mathrm{O} 2 k_{2}$, so that the number of feet per degree would only be increased by 2 per cent.

It is not likely that the two conductivities in the strata at Dukinfield are so unequal as even in the case of flagstone, so that 2 per cent. is a high estimate of the effect of their dip on the vertical rate of increase so far as pure conduction is concerned. The effect of dip in promoting the percolation of water is a distinct consideration, but the workings of the Dukinfield mines are so dry that this action does not seem to be important. ${ }^{3}$

\section{( $T o$ be continued.)}

\section{METAMORPHIC ROCKS OF BERGEN ${ }^{2}$}

$\Gamma \mathrm{HE}$ metamorphic rocks of the Bergen Peninsula in Norway continue to attract the attention of Norwegian geologists, and we have before us, as an addition to the well-known works

I Though the workings are dry there is a large quantity of water in the superincumbent strata

2 Hans H. Reusch, "Silurfcssiler og Pressede Konglomerater i Bergenskifrene."-Universitetsprogramm for förste Halvaar ( $188_{3}$ ). Kristiania, ז882. of Naumann, Leopold von Bucb, Esmark, Keilhau, Kjerulf, and Hjörtdal, a new elaborate and interesting nork by $M$. Hans $\mathrm{H}$. Reusch, which deals with the same : ubject. These rocks consist, as is known, of a variety of quartziferous talc-mica schists, diorite, clay-slates, conglomerates, and strongly-developed gneisses and granites. Various and very different opinions have been expressed as to the origin of these rocks. The researches of $M$. Reusch give a key to this question, as he has discovered in the clay-slates, which seem to constitute the upper part of these vertical strata, numerous fossils belonging to the lower part of the Upper Silurian formations, namely Halysites catenularia and Cyathophyllum, changed into white calcareous spar, a few tubular budies (presumably Syringophyllum organum), some gasteropods (Murchisonia or Subulites?) some trilobites, as Calymene, also Phacops or Dalmannites, and some brachiopeds. The presence ot these fossils is the more interesting as the whole series of schists was often considered as of igneous origin. As to the gneisses and gneisso-granites of the peninsula, M. Reusch has given great attention to their structure and to the remarkable results of pressure which the rocks have undergone. He shows how granitic veins n ere folded and crumpled, how a kind of transversal stratification has arisen in beds of stratified gneiss under the influence of pressure, and he concludes, from an accurate sludy of the subject, that altogether the rocks show a far greater degree of plasticity than wight have been supposed. "It seems that there are masses, as, for instance, the gneiss of Svenningdal, that have on one side a true stratified structure (not merely parallel or schistose structure) which could hardly be found in a rock of igneous origin, and on the other side send veins, or have included fragments which have undergone metamorphic changes."

One of the most attractive features of M. Reusch's work is the attention he has given to metamorphic phenomena and to changes caused by the pressure undergone by strata during their folding. The metamorphic phenomena were especially studied in the Osören district. The limestone which contains Silurian fossils' has become marble, and the cause of metamorphism was not contact with some eruptive rock, tut rather (as was observed in the Bernese Oberland by Swiss geologists) pressure and the molecular movements which pressure has occasioned in rocks. The clay, in which trilobites and other animals were entombed at Vagtdalen, has become a rock like muscovite-schist with porphyritically inclosed clusters of mica. As to the gneiss which appears among undoubtedly Silurian rocks, the author is inclined to consider it as sedimentary and as having been originally formed of loose materials. The granulite is clearly stratified and of sedimentary origin. The changes produced by the folding of strata and by the pressure they have undergone, are described with much accuracy and illustrated by many drawings. The fossils are nearly all compressed and elongated; the formerly conical coralla have received the shape of flat elongated biscuits, in accordance with the direction of pressure and stretching. The same is true with regard to all other fossils. In the green conglomerates at Osören, all the stones are flattened and elongated, acquiring thus a shape which they could not have possessed originally; very many of them have such a shape as to give in a cross-section the form of a lance-shaped leaf. The same structure, remarks the author, may be observed with the aid of a microscope in the "hones" from Eidsmarken in the South of Norway. Altogether the work of M. Reusch, although not rich in conclusions and generalisatione, will be a welcome addition to the accurate know ledge of the still little understood metamorphic rocks. The Norwegian text of this work is accompanied with a rather too short résumé in English.

P. K.

\section{CHEMICAL NOTES}

Carnelley [Chem. Soc. Ful. Trans., r88I, p. 317] has repeated his experiments on the effect of pressure on the melting. point of mercuric chloride, and has obtained results which show that this salt cannot be obtained in the solid state at temperatures appreciably above its melting-point.

JAHN [Berliner Berichte, xv. p. 1238] has made a series of careful determinations of the density of bromine vapour, which, when compared with similar observations on chlorine made by Ludwig, show that bromine vapour does not attain the normal density $\left(\mathrm{Br}=79^{\circ} 95\right)$ urtil it is heated to $160^{\circ}$ above its boilingpoint; and also that although chlorine exhibits smaller divergences from the normal density than bromine, it nevertheless 